\title{
Canadian Stroke Best Practice Recommendations, seventh edition: acetylsalicylic acid for prevention of vascular events
}

\author{
Theodore Wein MD, M. Patrice Lindsay RN PhD, David J. Gladstone MD PhD, Alexandre Poppe MD CM, \\ Alan Bell MD, Leanne K. Casaubon MD MSc, Norine Foley MSc, Shelagh B. Coutts MD MBChB, Jafna Cox MD, \\ James Douketis MD, Thalia Field MD MHSc, Laura Gioia MD MSc, Jeffrey Habert MD, Eddy Lang MD MDCM, \\ Shamir R. Mehta MD MSc, Christine Papoushek PharmD, William Semchuk PharmD MSc, Mikul Sharma MD MSc, \\ Jacob A. Udell MD MPH, Stephanie Lawrence BA Dip. J., Anita Mountain MD, Gord Gubitz MD, \\ Dar Dowlatshahi MD PhD, Anne Simard MHSc BJ, Andrea de Jong RN MN, Eric E. Smith MD MPH; \\ for the Heart and Stroke Foundation of Canada in collaboration with the Canadian Stroke Consortium
}

Cite as: CMAJ 2020 March 23;192:E302-11. doi: 10.1503/cmaj.191599

This article is available in French at www.cmaj.ca/lookup/suppl/doi:10.1503/cmaj.191599/-/DC1

CMAJ Podcasts: author interview at https://soundcloud.com/cmajpodcasts/191599-guide

I n 2016, 270204 people in Canada (excluding Quebec) were admitted to hospital for heart conditions, stroke and vascular cognitive impairment, including 107391 women and 162813 men, of whom 91524 died. ${ }^{1}$ This equates to 1 out of every 3 deaths in Canada and outpaces other diseases; $13 \%$ more people die of heart conditions, stroke or vascular cognitive impairment than die from all cancers combined. ${ }^{1}$

The benefits of acetylsalicylic acid (ASA) for secondary prevention of atherosclerotic cardiovascular disease are well established. In contrast, although low-dose ASA therapy for primary prevention of atherosclerotic cardiovascular disease was once commonly recommended, this practice is now being reconsidered in light of recent evidence. Three large randomized controlled trials on primary prevention found no net benefit of ASA for prevention of cardiovascular events or mortality in healthy older adults (defined in the ASPREE [Aspirin in Reducing Events in the Elderly] trial as $>65 \mathrm{yr}$ ) or persons with diabetes or other risk factors. ${ }^{2-4}$ Moreover, 2 recent systematic reviews incorporating the evidence from these trials provided somewhat conflicting results. ${ }^{5,6}$ Both found that the risk of major bleeding events was significantly increased in participants receiving ASA. However, 1 systematic review found that the use of ASA did not reduce the risk of all-cause mortality or ischemic stroke, ${ }^{6}$ while the other reported that ASA did reduce the risk of a composite of cardiovascular mortality, nonfatal myocardial infarction, nonfatal stroke and ischemic stroke. ${ }^{5}$

With greater awareness of the risks and benefits of ASA, overall lower rates of cardiovascular events in contemporary populations compared with those in older studies, and conflicting

\section{KEY POINTS}

- Acetylsalicylic acid is still strongly indicated for secondary prevention in patients who have had manifest cardiovascular, cerebrovascular or peripheral artery disease.

- Acetylsalicylic acid (ASA) is no longer recommended for primary prevention in individuals without a history of symptomatic cardiovascular disease, stroke or peripheral artery disease; the harms of daily ASA use could potentially outweigh the benefits.

- These revised recommendations present an opportunity for increased focus on primary prevention through healthy lifestyle choices, lifestyle modification and management of vascular risk factors.

- The decision to start, stop or continue ASA therapy is individualized, and the decision-making process should be shared between health professionals and patients, weighing risks, benefits, values and preferences.

- Important questions remain, including benefits of ASA for younger high-risk patients, individuals with subclinical vascular disease and asymptomatic atherosclerosis, and outcomes in patients who cease taking ASA after long-term use for primary prevention.

recommendations in guidelines and systematic reviews, clinicians are increasingly uncertain about the role of ASA for primary prevention. ${ }^{2}$ The actual number of people in Canada who are taking ASA prophylactically (either as prescribed by a health professional or of their own volition) is not known, although it is likely substantial. A US study reported results from a public poll that found 29 million people were taking ASA in that country, with $23 \%$ doing so without a physician's recommendation. ${ }^{7}$ 
This set of recommendations is intended to provide guidance for the use of ASA for primary prevention of vascular events. Additionally, the guideline comments on secondary stroke prevention to highlight the differences between these 2 distinct clinical areas. The recommendation regarding the use of ASA for the primary prevention of vascular events is a new addition to the Canadian Stroke Best Practice Recommendations portfolio from the Heart and Stroke Foundation of Canada. The recommendation on secondary stroke prevention is drawn from an existing set of recommendations on secondary prevention that was updated simultaneously.

These recommendations provide an evidence-based response to a need for guidance by health care professionals and the public, and to ensure alignment and consistency across other Canadian organizations such as the Canadian Cardiovascular Society and Thrombosis Canada, which have also issued previous recommendations and clinical guidance regarding ASA use in primary prevention. ${ }^{8,9}$ The goals of developing, disseminating and implementing these recommendations among health care providers and the public are to optimize evidence-based care across Canada, reduce practice variations and narrow the gap between current knowledge and clinical practice.

\section{Scope}

The Canadian Stroke Best Practice Recommendations are intended to provide up-to-date, evidence-based guidelines for the prevention and management of conditions that are of concern to the Heart and Stroke Foundation (including stroke, transient ischemic attack and vascular cognitive impairment, and considerations of related issues for people with these and heart conditions) and to promote optimal recovery and reintegration for people who have experienced or been affected by any of these conditions (i.e., patients, families and informal caregivers).

This current set of recommendations is unique for the Canadian Stroke Best Practice Recommendations in that it is not focused just on stroke; rather, it is applicable to the primary prevention of a range of conditions including cardiovascular disease, cerebrovascular disease, vascular cognitive impairment and peripheral arterial disease. This guideline includes recommendations for the use of ASA for both primary and secondary prevention. The recommendation on secondary prevention in this guideline is limited exclusively to ASA monotherapy and does not address the broader selection of antiplatelet agents currently available for this purpose. Recommendations on secondary prevention related to these agents can be found in the Canadian Stroke Best Practice Recommendations guideline on secondary prevention of stroke, which was updated in parallel to this guideline on ASA, using the same rigorous methodology. ${ }^{10}$

These recommendations are intended for use by all health care professionals across the continuum of care; people with lived experience of stroke, heart conditions, vascular disease and vascular cognitive impairment; and for the general public. Health system policy-makers, planners, funders, senior managers and administrators who are responsible for the coordination and delivery of health services within a province or region may also find this document relevant and applicable to their work.

\section{Recommendations}

Three recommendations have been developed regarding the use of ASA for prevention of vascular events (Box 1). The first reinforces the continued important role of ASA for secondary prevention in people who have already had a first vascular event. The second directly responds to new evidence and recommends against the use of ASA in healthy individuals without a history of vascular events. The third emphasizes the importance of shared decision-making between clinician and patient to ensure patient values and preferences are considered. More discussion of the evidence supporting the recommendations is available in Appendix 1 (at www.cmaj.ca/lookup/ suppl/doi:10.1503/cmaj.191599/-/DC2) and the full guideline (www. strokebestpractices.ca/recommendations/ASA-for-prevention).

\section{Secondary prevention}

Acetylsalicylic acid is strongly recommended for secondary prevention in individuals with symptomatic cardiovascular, cerebrovascular or peripheral arterial disease (evidence level A) ${ }^{11-13}$

The benefit of ASA for secondary prevention is well established. Daily, low-dose ASA reduces the risk of vascular events including myocardial infarction, stroke and vascular death in patients who have had a previous vascular event. The Antithrombotic Trialists' Collaboration (2002) has meta-analyzed data from many large trials showing consistent effects of ASA on preventing recurrent cardiovascular events. ${ }^{11}$ For example, treatment with ASA instead

Box 1: Recommendations for the use of acetylsalicylic acid (ASA) in the prevention of vascular events*

\section{Secondary prevention $\dagger$}

Acetylsalicylic acid is strongly recommended for secondary prevention in individuals with symptomatic cardiovascular, cerebrovascular or peripheral arterial disease (evidence level A). ${ }^{11-13}$

\section{Primary prevention}

The use of ASA is not recommended for primary prevention of a first vascular event (evidence level A). ${ }^{2-4,6}$

- This recommendation pertains to individuals with vascular risk factors who have not had a vascular event (evidence level A) 2,4,6 and for healthy older individuals without vascular risk factors (evidence level B). ${ }^{3}$

- The net benefit of ASA in individuals with asymptomatic atherosclerosis is uncertain (evidence level B)..$^{14,15}$

\section{Shared decision-making}

Health professionals (such as physicians [primary care or subspecialty], nurses and nurse practitioners, pharmacists, physician assistants) should engage patients and caregivers in discussions regarding the use of ASA for primary prevention of vascular disease. An individual's risk, benefit, values and preferences should be considered in order to make an informed shared decision to start, continue or stop ASA for primary prevention of vascular disease (evidence level B). ${ }^{16,17}$

*Please refer to Appendix 2 for evidence tables comparing elements of randomized trials and systematic reviews.

†For additional information regarding the use of ASA and other antiplatelet agents in secondary prevention, please see the Canadian Stroke Best Practice Recommendations Secondary Prevention of Stroke Module, ${ }^{10}$ Canadian Cardiovascular Society guideline on antiplatelet and anticoagulant use, ${ }^{9}$ and Thrombosis Canada clinical guides. ${ }^{8}$ 
of placebo reduced the number of serious vascular events by 36 (standard error [SE] 5) per 1000 per year in patients with a previous myocardial infarction and also by 36 (SE 6) per 1000 per year in patients with a previous history of stroke or transient ischemic attack. In patients with peripheral arterial disease, treatment with ASA instead of placebo reduced the odds of serious vascular events by $23 \%$ (SE 8\%). Similar risk reductions were seen for patients with stable or unstable angina. ${ }^{11}$ More information on the evidence supporting this recommendation is available at www. strokebestpractices.ca/recommendations/ASA-for-prevention.

\section{Primary prevention}

The use of acetylsalicylic acid is not recommended for primary prevention of a first vascular event (evidence level $A$ ). ${ }^{2-4,6}$

- This recommendation pertains to individuals with vascular risk factors who have not had a vascular event (evidence level A), 2,4,6 and for healthy older individuals without vascular risk factors (evidence level $B$ ). ${ }^{3}$

- The net benefit of acetylsalicylic acid in individuals with asymptomatic atherosclerosis is uncertain (evidence level B). ${ }^{14,15}$

\section{Reduction in vascular events}

We derived the evidence base used to formulate the recommendation regarding ASA use for primary prevention mainly from 3 recently published randomized controlled trials (RCTs). Each trial assessed the potential benefit of $100 \mathrm{mg}$ of ASA versus placebo in people without pre-existing cardiovascular disease, which was defined slightly differently in each trial (Appendix 2, available at www.cmaj.ca/lookup/suppl/doi:10.1503/cmaj.191599/-/DC2).

All trials included large sample sizes ( $>12000$ to $>19000$ participants). The ARRIVE2 (Aspirin to Reduce Risk of Initial Vascular Events) trial included men aged $\geq 55$ years with 2 to 4 cardiovascular risk factors and women aged $\geq 60$ years with 3 or more risk factors, and excluded people with diabetes. The ASPREE ${ }^{3}$ trial involved men and women from Australia and the United States who were aged $\geq 70$ years (or $\geq 65$ years among black and Hispanic people in the US). The ASCEND 4 (A Study of Cardiovascular Events in Diabetes) trial included men and women aged $\geq 40$ years with type 1 or 2 diabetes. The mean age of participants was 64 years in the ARRIVE ${ }^{2}$ and ASCEND $^{4}$ trials, and the median age in the ASPREE trial ${ }^{3}$ was 74 years. Current use of ASA or anticoagulants was an exclusion criterion in all trials; however, $36 \%$ of participants in the ASCEND trial ${ }^{4}$ had used ASA before screening, while $11 \%$ had used ASA previously in the ASPREE trial. ${ }^{3}$ Median duration of follow-up ranged from 4.7 to 7.1 years.

The results of 2 trials were negative (ARRIVE, ${ }^{2}$ ASPREE ${ }^{3}$ ), whereby the risks of cardiovascular events were not significantly lower in the ASA-treated group. In the ARRIVE ${ }^{2}$ and ASPREE $^{3}$ trials, the hazard ratios associated with ASA use for the primary outcome were 0.96 (95\% confidence interval [Cl] 0.81-1.13) and 0.95 (95\% Cl 0.83-1.08), respectively. In the ASCEND trial, ${ }^{4}$ the risk of the primary outcome (first serious vascular event [myocardial infarction, stroke, transient ischemic attack or cardiovascular death]) was significantly lower in the ASA group (8.5\% v. 9.6\%; relative risk [RR] 0.88, 95\% Cl 0.79-0.97).

The results of these 3 trials were incorporated into 2 systematic reviews, the results of which conflicted. ${ }^{5,6}$ The use of ASA did not reduce the risk of all-cause mortality or ischemic stroke ${ }^{6}$ but did reduce the risk of a composite outcome of cardiovascular mortality, nonfatal myocardial infarction, nonfatal stroke and ischemic stroke. ${ }^{5}$ Each of these reviews included the results of the same 11 RCTs, but the review by Zheng and Roddick ${ }^{5}$ included 2 additional trials (POPADAD [Prevention of Progression of Arterial Disease and Diabetes] 2008, ${ }^{18}$ and AAA [Aspirin for Asymptomatic Atherosclerosis] 2010 14 ). The inclusion criteria were restricted to participants who had no previous cardiovascular disease in 1 review, ${ }^{5}$ and the other included people without a previous history of atherosclerosis. ${ }^{6}$

\section{Risks}

In the 3 aforementioned trials (ASPREE, ${ }^{3}$ ARRIVE $^{2}$ and ASCEND $^{4}$ ), the risk of major bleeding events increased significantly with ASA therapy (ASPREE: hazard ratio [HR] 1.38, 95\% Cl 1.18-1.62; ARRIVE [any gastrointestinal bleeding]: HR $2.11,95 \% \mathrm{Cl} 1.36-$ 3.28; and ASCEND: RR 1.29, 95\% Cl 1.09-1.52).

In a systematic review and meta-analysis designed specifically to examine the risk of intracranial hemorrhage associated with the use of ASA, Huang and colleagues ${ }^{19}$ included the results of 13 RCTs ( $n=134446)$ that comprised individuals without pre-existing symptomatic cardiovascular diseases (e.g., coronary artery disease, stroke or peripheral artery disease). The trials compared low-dose ASA ( $\leq 100 \mathrm{mg} / \mathrm{d}$ for $\geq 6 \mathrm{mo}$ ) versus placebo or no treatment, and examined intracranial bleeding outcomes exclusively. The use of ASA was associated with a significantly increased risk of any intracranial bleeding ( $R R$ 1.37, 95\% Cl 1.13-1.66; $n=8$ trials; 2 additional intracranial hemorrhages in 1000 people). In a sensitivity analysis, excluding the results from the ASPREE trial, ${ }^{3}$ which included older people only ( $>65 \mathrm{yr}$ and $\geq 70 \mathrm{yr}$, depending on race), the risk became nonsignificant. Acetylsalicylic acid was not associated with a significantly increased risk of intracerebral hemorrhage or subarachnoid hemorrhage. In subgroup analysis, participants with Asian ethnicity and people with a body mass index $<25$ taking ASA were at significantly higher risk for intracerebral hemorrhage. The risk of major bleeding was also increased in the results of 2 other recent meta-analyses.,

\section{Areas of uncertainty}

Owing to insufficient evidence of benefit of ASA for primary prevention of major adverse cardiovascular events, there is no rationale for using ASA for primary prevention in patients at any level of risk, including those at higher risk. However, MarquisGravel and colleagues ${ }^{20}$ highlighted several areas of uncertainty that remain regarding the use of ASA for primary prevention after the completion of the ARRIVE, ASPREE and ASCEND trials. Factors such as body weight and sex were identified as potential effect modifiers. In a meta-analysis of pooled individual patient data from $10 \mathrm{RCTs},{ }^{21}$ the risk of cardiovascular events associated with the use of 75-100 mg ASA for primary prevention decreased with increasing weight, while low-dose ASA had the greatest preventive effect among those participants weighing 50-69 kg. In the same study, ASA doses of $350 \mathrm{mg}$ and $500 \mathrm{mg}$ for primary prevention were associated with decreased risk of cardiovascular events in people weighing $\geq 70 \mathrm{~kg}$. 
Acetylsalicylic acid has also been evaluated with respect to its efficacy for reducing the risk of cardiovascular events including transient ischemic attack, stroke, myocardial infarction, unstable angina or death among people with asymptomatic atherosclerosis. Although it has been suggested that low-dose ASA leads to a change in the composition of plaque within blood vessels, the use of $325 \mathrm{mg}$ of daily ASA for 2 years in people with carotid stenosis ( $\geq 50 \%$ ) was not associated with reductions in vascular events compared with placebo. ${ }^{15}$

The role of sex as a potential effect modifier is less clear, as we identified no significant interactions between sex and the effectiveness of ASA in the ARRIVE, ASCEND or ASPREE trials. In an older meta-analysis, which included the results of 6 RCTs, Berger and colleagues ${ }^{22}$ suggested that ASA reduced the risk of myocardial infarction only in men, and the risk of all stroke and ischemic strokes only in women. The role of gender was not discussed in the results of any of these trials.

\section{Shared decision-making}

Health professionals (such as physicians [primary care or subspecialty], nurses and nurse practitioners, pharmacists, physician assistants) should engage patients and caregivers in discussions regarding the use of acetylsalicylic acid for primary prevention of vascular disease. An individual's risk, benefit, values and preferences should be considered in order to make an informed shared decision to start, continue or stop acetylsalicylic acid for primary prevention of vascular disease (evidence level B). ${ }^{16,17}$

Although long-term use of ASA is not recommended for the primary prevention of a first vascular event in these recommendations, there is recognition that the decision to start, continue or stop ASA therapy should be highly individualized, following an assessment of the benefit-risk ratio and a clinician-patient discussion regarding potential benefits and harms, and alternatives. This process of shared decision-making is based on both clinical evidence and the patient's informed preferences and values. ${ }^{23,24}$

For most patients, stopping ASA will be the best choice. However, some individuals may choose to remain on ASA for personal reasons, such as having a strong family history of vascular disease, or if they value prevention of vascular events more than avoiding the harm of major bleeding.

There is currently no evidence that directly addresses the role of shared decision-making in the context of ASA for primary prevention, although interventions to support shared decisionmaking have been evaluated for the treatment of hypertension, ${ }^{25,26}$ atrial fibrillation ${ }^{27}$ and diabetes. ${ }^{28}$

\section{Methods}

\section{Guideline panel composition}

An interdisciplinary expert writing group panel was convened by the Heart and Stroke Foundation of Canada to review the literature and address the utility of ASA use for primary prevention of vascular events. The panel included stroke neurologists, cardiologists, thrombosis specialists, family physicians, an emergency medicine physician, a physiatrist, pharmacists, nurses and an epidemiologist. Members were selected after a call for nominations for participants for the Canadian Stroke Best Practice Recommendations primary and secondary prevention writing group panels. The writing group chair (T.W.) and members of the Canadian Stroke Best Practice Recommendations Advisory Committee selected the 18 members of the primary writing group panel, ensuring geographic, urban and rural, and interdisciplinary representation; gender balance; and years of experience.

As part of the Canadian Stroke Best Practice Recommendations methodology, a Community Consultation and Review Panel, composed of 8 patients and caregivers, took part in the review and development of these recommendations, ${ }^{29}$ jointly with the writing group.

A group of 15 external reviewers, who were not involved in the guideline development process, was convened to conduct a final review of the guideline. The external review panel had a similar composition across disciplines as the writing group panel. They were selected from our original list of nominees who were not chosen for the writing group, and through review of the literature to identify knowledgeable professionals on this topic.

These recommendations were developed in collaboration with the Canadian Stroke Consortium, with several members of the consortium (T.W., D.J.G., A.P., L.K.C., S.B.C., T.F., L.G., M.S., G.G., D.D. and E.E.S.) participating in the guideline writing group. The Canadian Cardiovascular Society also had 2 official representatives (J.C., J.A.U.) participate as writing group members.

\section{Guideline development}

The process for developing and updating the Canadian Stroke Best Practice Recommendations follows a rigorous, standardized framework adapted from the Practice Guideline Evaluation and Adaptation Cycle, ${ }^{30,31}$ and addresses all criteria defined within the Appraisal of Guidelines for Research and Evaluation (AGREE) Trust model. ${ }^{32}$ The methodology has been applied in previously published Canadian Stroke Best Practice Recommendations updates and can be found on the Canadian Stroke Best Practices website at www.strokebestpractices.ca.

Experienced personnel conducted literature searches to identify peer-reviewed literature that examined the use of ASA monotherapy for the prevention of vascular events, and the role of shared decisionmaking for vascular risk reduction. We included systematic reviews, meta-analyses, randomized controlled trials and observational studies, as available. The literature for this module was current to November 2019. The search strategy is available in Appendix 2.

Following a standardized abstraction format, evidence tables were constructed by experienced personnel, including content from selected studies, and these were provided to the writing group for review. The writing group discussed and debated the strength, importance, clinical relevance and applicability of the evidence and, through consensus, developed a draft set of proposed recommendations. During this process, we identified additional literature and used it as we developed a final set of proposed recommendations. Definitions of terms used within the recommendations (e.g., primary prevention, secondary prevention) are available at www.strokebestpractices.ca/recommendations/ ASA-for-prevention.

We assigned each recommendation a level indicating the strength of the evidence, ranging from $A$ to $C$, according to the 
criteria defined in Box 2. These criteria are adapted from work by Guyatt and colleagues. ${ }^{33}$ When developing and including "C-level" recommendations, we obtained consensus among the writing group and validated it through the internal and external review process. We used this level of evidence cautiously, and only when there was a lack of stronger evidence for the topics of interest, and the writing group thought that some guidance was warranted for these areas.

During the work of developing the recommendations for the use of ASA for primary prevention, we became concerned about potential confusion regarding the use of ASA for secondary prevention among the public and health care providers. Most members could cite several instances in their clinical practices where patients with a history of stroke or coronary artery disease had stopped ASA on their own, based on exposure to media coverage of the new trials for ASA for primary prevention. Accordingly, we decided to expand the scope of this guideline to include a recommendation on secondary prevention. This recommendation was developed jointly with a separate guideline writing group working on secondary prevention of stroke, following the rigorous guideline development process for the Canadian Stroke Best Practice Recommendations. Several members of the primary prevention writing group participated in both groups. A full description of the methodology for the secondary prevention guideline can be found at strokebestpractices.ca.

\section{Review}

The draft set of recommendations underwent an internal review by the Canadian Stroke Best Practice Recommendations Advisory Committee, and was then sent to the external review group for review. The draft recommendations were also sent to the Canadian Stroke Consortium, Canadian Cardiovascular Society, Thrombosis Canada, the Canadian Society of Hospital Pharmacists and the Canadian Pharmacists Association for their review and consideration for endorsement. We gave all feedback careful consideration during the editing process and incorporated it into the final version of the recommendations as appropriate.
The guidelines are endorsed by the Canadian Stroke Consortium, Canadian Cardiovascular Society, Thrombosis Canada, the Canadian Society of Hospital Pharmacists, the Canadian Pharmacists Association and the Nurse Practitioners' Association of Ontario.

More information on the guideline methods can be found in the full guideline, available at www.strokebestpractices.ca/ recommendations/ASA-for-prevention. We will update these recommendations regularly, every 2 to 3 years, to integrate emerging evidence.

\section{Management of competing interests}

All potential participants in the recommendation development and review process were required to sign confidentiality agreements and to declare all direct and indirect competing interests in writing. Any declared competing interests were reviewed by the Chairs of the Canadian Stroke Best Practice Recommendations Advisory Committee and appropriate staff members of the Heart and Stroke Foundation of Canada with respect to potential impact. Potential members of the writing group who had direct competing interests were not invited to participate.

We identified participants who had indirect competing interests for a topic area at the beginning of discussions for that topic. The writing group and external reviewers work in a wide range of health care settings. This interdisciplinary approach ensured that the perspectives of relevant health disciplines and care settings were considered in the development of the recommendations, and no one member was more influential than the others, thus mitigating the risk of potential or real competing interests from individual members.

Given there were no direct competing interests related to ASA, all members participated in the voting process. All $18 \mathrm{mem}$ bers voted in support of the recommendations on secondary prevention and shared decision-making, and 17 of 18 members voted in support of the recommendation on primary prevention. Therefore, any potential indirect competing interests were mitigated by the broad support across the members of the writing group panel.

\section{Box 2: Description of levels of evidence reported in Canadian Stroke Best Practice Recommendations ${ }^{33}$}

Level of evidence

A

B

C

Clinical consideration

\section{Criteria}

Evidence from a meta-analysis of RCTs or consistent findings from 2 or more RCTs. Desirable effects clearly outweigh undesirable effects or vice versa.

Phrases used in recommendations with this level of evidence include "strong recommendation"; actions "should be (or not be) done."

Evidence from a single RCT or consistent findings from 2 or more well-designed nonrandomized or noncontrolled trials, and large observational studies. Meta-analysis of nonrandomized or observational studies. Desirable effects outweigh or are closely balanced with undesirable effects, or vice versa.

Phrases used in recommendations with this level of evidence include "is recommended"; "should be considered"; and in some cases where there is strong agreement by the writing group, "actions should be (or not be) done on most or specific groups as applicable."

Writing group consensus on topics supported by limited research evidence. Desirable effects outweigh or are closely balanced with undesirable effects or vice versa, as determined by writing group consensus.

Phrases used in recommendations with this level of evidence include "may be considered" or "is reasonable."

Reasonable practical advice provided by consensus of the writing group on specific clinical issues that are common or controversial and lack research evidence to guide practice.

No evidence levels are assigned to clinical considerations. 


\section{Implementation}

These recommendations are accompanied by supporting information found at www.strokebestpractices.ca/recommendations/ ASA-for-prevention. This information includes a rationale for including this topic in the Canadian Stroke Best Practice Recommendations, which describes the problem and burden; system implications to ensure the structural elements and resources are available to achieve recommended levels of care, including professional education and public awareness efforts; performance measures to monitor implementation, care delivery and patient outcomes; implementation resources for clinicians and the public to support integration of the actions within the recommendations to daily practice; and a more detailed summary of the evidence on which the recommendations were based. Knowledge translation information for the recommendations can also be found on the website.

A wide range of professional and public education activities are planned that include messaging on mainstream and social media, public and health professional webinars, presentation at conferences, email campaigns and inclusion in newsletters for health professionals and the public, updated information on Heart and Stroke Foundation of Canada websites and on those of the professional groups that endorsed these recommendations, and an infographic explaining the recommendations to the public.

At the practice level, we advise that people taking ASA for primary prevention be informed of the newest evidence that suggests there is less benefit than previously believed and that newer guidelines recommend against it. Practitioners are strongly encouraged to promote medical, lifestyle and behavioural changes that are more effective than ASA in preventing cardiovascular events, including management of hypertension, diabetes and hypercholesterolemia; smoking cessation; increased physical activity; maintaining a healthy weight; and eating a healthy diet. ${ }^{34,35}$

\section{Other guidelines}

This guideline includes the most recent clinical trials and systematic reviews on this topic. In contrast to some previous guidelines, we do not recommend ASA for primary prevention of a first vascular event for any subgroups, including patients at higher estimated 10-year risk. Recent trials fail to provide consistent evidence that ASA reduces the risk of first vascular events, with clear evidence of increased harm from major bleeding.

An earlier guideline issued by the Canadian Cardiovascular Society in 2011 stated that antiplatelet therapy was not recommended in individuals without cardiovascular disease because of the increased risk of major bleeding. ${ }^{9}$ The 2016 European guideline on prevention of cardiovascular disease ${ }^{36}$ includes similar recommendations. In 2018, Thrombosis Canada suggested that ASA be used only in special circumstances for primary prevention of cardiovascular morbidity and mortality. ${ }^{8}$
The current 2019 American College of Cardiology/American Heart Association guideline on the primary prevention of cardiovascular disease suggests that low-dose ASA (75-100 mg/d) might be considered among selected adults aged $40-70$ years at higher risk of cardiovascular disease, and should be avoided in persons aged $>70$ years. ${ }^{37}$ This language was modified from the 2014 recommendation, which stated that "the use of ASA for cardiovascular (including but not specific to stroke) prophylaxis is reasonable for people whose risk is sufficiently high (10year risk $>10 \%$ ) for the benefits to outweigh the risks associated with treatment." 38

In 2016, the US Preventive Services Task Force made agespecific recommendations, suggesting that individuals aged 50 to 59 years start low-dose ASA if their 10-year cardiovascular risk is $>10 \%$ and the risk of bleeding is not increased. For those aged 60 to 69 years, the recommendation was for the decision to be a personal one, given a similar 10-year risk; the task force suggested the evidence was insufficient to make recommendations for people younger than 50 years or older than 69 years. ${ }^{39}$ The Canadian Task Force on Preventive Health Care has not published recommendations on this topic. Box 3 includes details of the guidelines reviewed and discussed by the writing group.

\section{Gaps in knowledge}

The recent evidence and the accumulating guidance that routine use of ASA is not recommended for primary prevention of vascular disease will likely lead to a substantial shift in approaches to primary prevention of vascular disease and public perception and affect clinical practice. However, important questions remain that have not yet been addressed by research.

Most trials have focused on older people because they are generally at the highest risk of new cardiovascular events; whether ASA could provide net benefit in younger, very highrisk patients with lower likelihood of gastrointestinal bleeding is possible but unproven. With increasing sensitivity of imaging, it is possible to identify persons with subclinical disease (such as silent myocardial infarction or stroke, or asymptomatic atherosclerosis) but it is not clear whether these patients would derive more benefit from ASA. The available trials in such populations fail to show that ASA makes a clinically substantial difference in the risk of firstever clinical events. ${ }^{14,15}$

Finally, there is the challenging question of how to advise patients who have been taking ASA for primary prevention for many years without experiencing adverse events such as gastrointestinal bleeding. There is a paucity of research on outcomes after ceasing daily ASA use in this setting, with no controlled trials. Stopping ASA may not be advisable in all patients if there are rebound prothrombotic effects from doing so. Further, the shared decision-making literature does not address this specific topic and poses an opportunity to apply the principles of shared decision-making on this subject, which likely affects a substantial number of Canadians. 
Box 3: Statements from other guidelines on the use of ASA for primary prevention of vascular events

Organization (year)

American Diabetes Association (2019) ${ }^{40}$

ACC/AHA Guideline on the Primary Prevention of Cardiovascular Disease $(2019)^{37}$

Thrombosis Canada (2018)

USPSTF $(2016)^{39}$

The Sixth Joint Task Force of the European Society of Cardiology and Other Societies on Cardiovascular Disease Prevention in Clinical Practice (2016)

American College of Chest Physicians $(2012)^{41}$

Canadian Cardiovascular Society $(2011)^{9}$
Recommendation*

- Aspirin therapy (75-162 mg daily) may be considered as a primary prevention strategy in those with diabetes who are at increased risk of CVD, after a discussion with the patient on the benefits versus increased risk of bleeding (evidence level C).

- Low-dose aspirin (75-100 mg orally daily) might be considered for the primary prevention of ASCVD among select adults 40 to 70 years of age who are at higher ASCVD risk but not at increased bleeding risk (class Ilb recommendation, evidence level A).

- Low-dose aspirin (75-100 mg orally daily) should not be administered on a routine basis for the primary prevention of ASCVD among adults $>70$ years of age (class III recommendation, evidence level B-R).

- Low-dose aspirin (75-100 mg orally daily) should not be administered for the primary prevention of ASCVD among adults of any age who are at increased risk of bleeding (class III recommendation, evidence level C-LD).

- Only in special circumstances in patients without manifest vascular disease in whom vascular risk is considered high and bleeding risk is considered low. Examples include: asymptomatic carotid or coronary atherosclerosis demonstrated on vascular imaging studies and patients at very high risk of vascular events due to multiple cardiovascular risk factors. (No evidence levels provided in Thrombosis Canada statements.)

- The USPSTF recommends initiating low-dose aspirin use for the primary prevention of CVD and CRC in adults aged 50 to 59 years who have a 10\% or greater 10-year CVD risk, are not at increased risk for bleeding, have a life expectancy of at least 10 years, and are willing to take low-dose aspirin daily for at least 10 years (grade B recommendation).

- The decision to initiate low-dose aspirin use for the primary prevention of CVD and CRC in adults aged 60 to 69 years who have a 10\% or greater 10-year CVD risk should be an individual one. Persons who are not at increased risk for bleeding, have a life expectancy of at least 10 years, and are willing to take low-dose aspirin daily for at least 10 years are more likely to benefit. Persons who place a higher value on the potential benefits than the potential harms may choose to initiate low-dose aspirin (grade $\mathrm{C}$ recommendation).

- The current evidence is insufficient to assess the balance of benefits and harms of initiating aspirin use for the primary prevention of CVD and CRC in adults younger than 50 years (I statement).

- The current evidence is insufficient to assess the balance of benefits and harms of initiating aspirin use for the primary prevention of CVD and CRC in adults aged 70 years or older (I statement).

- Antiplatelet therapy is not recommended in individuals free from CVD, due to the increased risk of major bleeding (class III recommendation; evidence level B).

- For persons aged 50 years or older without symptomatic CVD, we suggest low-dose aspirin 75 to $100 \mathrm{mg}$ daily over no aspirin therapy (grade 2B).

- For men and women without evidence of manifest vascular disease, the use of ASA at any dose is not recommended for routine use to prevent ischemic vascular events (class III recommendation; evidence level A).

- For men and women without evidence of manifest vascular disease, the use of clopidogrel $75 \mathrm{mg}$ daily plus ASA at any dose is not recommended to prevent ischemic vascular events (class III recommendation; evidence level B).

- In special circumstances in men and women without evidence of manifest vascular disease in whom vascular risk is considered high and bleeding risk is low, ASA 75-162 mg daily may be considered (class IIb recommendation; evidence level C).

Note: $\mathrm{ACA} / \mathrm{AHA}=$ American College of Cardiology $/$ American Heart Association, $\mathrm{ASA}=$ acetylsalicylic acid, $\mathrm{ASCVD}=$ atherosclerotic cardiovascular disease, $\mathrm{CRC}=\mathrm{colorectal}$ cancer, $\mathrm{CVD}=$ cardiovascular disease, USPSTF = US Preventive Services Task Force.

*Definitions of the class or strength of recommendations and level of evidence can be found in the cited guidelines.

\section{Conclusion}

The use of ASA for prevention (primary and secondary) of vascular events has been a common practice in Canada and elsewhere for decades. Based on a reappraisal of the evidence in light of recent publications of large neutral trials, we now recommend that ASA no longer be routinely used for primary prevention in most individuals. The general population should be advised that daily ASA is not recommended for primary prevention of vascular events because the bleeding risks potentially outweigh the benefits. 
Acetylsalicylic acid is still strongly recommended for secondary prevention in patients who have had manifest cardiovascular, cerebrovascular or peripheral artery disease.

The decision to start, stop or continue ASA therapy is individualized and the decision-making process should be shared between health professionals and patients, after weighing the risks, benefits, values and preferences.

Finally, clinicians are strongly encouraged to promote medical, lifestyle and behavioural changes that are more effective than ASA in preventing cardiovascular events.

These recommendations are intended to change practice, increase awareness, and drive policy, systems change and quality improvement for prevention of vascular events, as well as further highlight the importance of ensuring supportive environments and effective strategies for primary prevention.

\section{References}

1. (Dis)connected: how unseen links are putting us at risk - 2019 report on heart, stroke and vascular cognitive impairment. Available: www.heartandstroke.ca/-/media/pdf -files/canada/2019-report/heartandstrokereport2019.ashx (accessed 2019 Nov. 22).

2. Gaziano JM, Brotons C, Coppolecchia R, et al.; ARRIVE Executive Committee. Use of aspirin to reduce risk of initial vascular events in patients at moderate risk of cardiovascular disease (ARRIVE): a randomised, double-blind, placebocontrolled trial. Lancet 2018;392:1036-46.

3. McNeil JJ, Nelson MR, Woods RL, et al.; ASPREE Investigator Group. Effect of aspirin on all-cause mortality in the healthy elderly. NEngl J Med 2018;379:1519-28.

4. ASCEND Study Collaborative Group; Bowman L, Mafham M, Wallendszus K, et al. Effects of aspirin for primary prevention in persons with diabetes mellitus. N Engl J Med 2018;379:1529-39.

5. Zheng SL, Roddick AJ. Association of aspirin use for primary prevention with cardiovascular events and bleeding events: a systematic review and metaanalysis. JAMA 2019;321:277-87.

6. Mahmoud AN, Gad MM, Elgendy AY, et al. Efficacy and safety of aspirin for primary prevention of cardiovascular events: a meta-analysis and trial sequential analysis of randomized controlled trials. Eur Heart J 2019;40:607-17.

7. O'Brien CW, Juraschek SP, Wee CC. Prevalence of aspirin use for primary prevention of cardiovascular disease in the United States: results from the 2017 National Health Interview Survey. Ann Intern Med 2019 July 23 [Epub ahead of print]. doi: 10.7326/M19-0953.

8. Acetylsalicylic acid (ASA). Whitby (ON): Thrombosis Canada; 2018. Available: https://thrombosiscanada.ca/wp-content/uploads/2019/01/Acetylsalicyclic-Acid -2018July24-Final.pdf (accessed 2019 Nov. 22).

9. Bell AD, Roussin A, Cartier R, et al.; Canadian Cardiovascular Society. The use of antiplatelet therapy in the outpatient setting: Canadian Cardiovascular Society guidelines. Can J Cardiol 2011;27(Suppl A):S1-59.

10. Wein T, Lindsay MP, Côté R, et al.; Heart and Stroke Foundation Canadian Stroke Best Practice Committees. Canadian stroke best practice recommendations: secondary prevention of stroke, sixth edition practice guidelines, update 2017. Int J Stroke 2018;13:420-43.

11. Antithrombotic Trialists' Collaboration. Collaborative meta-analysis of randomised trials of antiplatelet therapy for prevention of death, myocardial infarction, and stroke in high risk patients. BMJ 2002;324:71-86.

12. Antithrombotic Trialists' (ATT) Collaboration; Baigent C, Blackwell L, Collins R, et al. Aspirin in the primary and secondary prevention of vascular disease: collaborative meta-analysis of individual participant data from randomised trials. Lancet 2009;373:1849-60.

13. Berger JS, Brown DL, Becker RC. Low-dose aspirin in patients with stable cardiovascular disease: a meta-analysis. Am J Med 2008;121:43-9.

14. Fowkes FG, Price JF, Stewart MC, et al.; Aspirin for Asymptomatic Atherosclerosis Trialists. Aspirin for prevention of cardiovascular events in a general population screened for a low ankle brachial index: a randomized controlled trial. JAMA 2010;303:841-8
15. Côté R, Battista RN, Abrahamowicz M, et al. Lack of effect of aspirin in asymptomatic patients with carotid bruits and substantial carotid narrowing. The Asymptomatic Cervical Bruit Study Group. Ann Intern Med 1995;123: 649-55.

16. Sepucha KR, Scholl I. Measuring shared decision making: a review of constructs, measures, and opportunities for cardiovascular care. Circ Cardiovasc Qual Outcomes 2014;7:620-6.

17. Alonso-Coello P, Montori VM, Díaz MG, et al. Values and preferences for oral antithrombotic therapy in patients with atrial fibrillation: physician and patient perspectives. Health Expect 2015;18:2318-27.

18. Belch J, MacCuish A, Campbell I, et al.; Prevention of Progression of Arterial Disease and Diabetes Study Group; Diabetes Registry Group; Royal College of Physicians Edinburgh. The prevention of progression of arterial disease and diabetes (POPADAD) trial: factorial randomised placebo controlled trial of aspirin and antioxidants in patients with diabetes and asymptomatic peripheral arterial disease. BMJ 2008;337:a1840.

19. Huang WY, Saver JL, Wu YL, et al. Frequency of intracranial hemorrhage with low-dose aspirin in individuals without symptomatic cardiovascular disease: a systematic review and meta-analysis. JAMA Neurol 2019 May 13 [Epub ahead of print]. doi: 10.1001/jamaneurol.2019.1120.

20. Marquis-Gravel G, Roe MT, Harrington RA, et al. Revisiting the role of aspirin for the primary prevention of cardiovascular disease. Circulation 2019;140: 1115-24.

21. Rothwell PM, Cook NR, Gaziano JM, et al. Effects of aspirin on risks of vascular events and cancer according to bodyweight and dose: analysis of individual patient data from randomised trials. Lancet 2018;392:387-99.

22. Berger JS, Roncaglioni MC, Avanzini F, et al. Aspirin for the primary prevention of cardiovascular events in women and men: a sex-specific meta-analysis of randomized controlled trials. JAMA 2006;295:306-13.

23. Charles C, Gafni A, Whelan T. Shared decision-making in the medical encounter: what does it mean? (or it takes at least two to tango). Soc Sci Med 1997;44:681-92.

24. Grad R, Légaré F, Bell NR, et al. Shared decision making in preventive health care: what it is; what it is not. Can Fam Physician 2017;63:682-4.

25. Johnson RA, Huntley A, Hughes RA, et al. Interventions to support shared decision making for hypertension: a systematic review of controlled studies. Health Expect 2018;21:1191-207.

26. Tinsel I, Buchholz A, Vach W, et al. Shared decision-making in antihypertensive therapy: a cluster randomised controlled trial. BMC Fam Pract 2013; $14: 135$.

27. Loewen PS, Bansback N, Hicklin J, et al. Evaluating the effect of a patient decision aid for atrial fibrillation stroke prevention therapy. Ann Pharmacother 2019;53:665-74.

28. Bailey RA, Pfeifer M, Shillington AC, et al. Effect of a patient decision aid (PDA) for type 2 diabetes on knowledge, decisional self-efficacy, and decisional conflict. BMC Health Serv Res 2016;16:10.

29. Harris J, Teed M, Gierman N, et al. Bringing the patient voice to life in stroke best practice guidelines [abstract]. Int J Stroke 2018;13:102. doi: 10.1177 $/ 1747493018789543$

30. Graham ID, Harrison MB, Brouwers M, et al. Facilitating the use of evidence in practice: evaluating and adapting clinical practice guidelines for local use by health care organizations. J Obstet Gynecol Neonatal Nurs 2002;31:599-611.

31. Vernooij RW, Alonso-Coello P, Brouwers M, et al.; CheckUp Panel. Reporting items for updated clinical guidelines: checklist for the reporting of updated guidelines (CheckUp). PLoS Med 2017;14:e1002207.

32. Brouwers MC, Kho ME, Browman GP, et al.; AGREE Next Steps Consortium. AGREE II: advancing guideline development, reporting and evaluation in health care. CMAJ 2010;182:E839-42.

33. Guyatt GH, Cook DJ, Jaeschke R, et al. Grades of recommendation for antithrombotic agents: American College of Chest Physicians Evidence-Based Clinical Practice Guidelines (8th Edition). Chest 2008;133(Suppl): 123S-31S.

34. Yusuf S, Hawken S, Ounpuu S, et al.; INTERHEART Study Investigators. Effect of potentially modifiable risk factors associated with myocardial infarction in 52 countries (the INTERHEART study): case-control study. Lancet 2004;364: 937-52. 
35. O'Donnell MJ, Chin SL, Rangarajan S, et al.; INTERSTROKE investigators. Global and regional effects of potentially modifiable risk factors associated with acute stroke in 32 countries (INTERSTROKE): a case-control study. Lancet 2016;388:761-75

36. Piepoli MF, Hoes AW, Agewall S, et al.; ESC Scientific Document Group. 2016 European Guidelines on cardiovascular disease prevention in clinical practice: The Sixth Joint Task Force of the European Society of Cardiology and Other Societies on Cardiovascular Disease Prevention in Clinical Practice (constituted by representatives of 10 societies and by invited experts) Developed with the special contribution of the European Association for Cardiovascular Prevention \& Rehabilitation (EACPR). Eur Heart J 2016;37: 2315-81.

37. Arnett DK, Blumenthal RS, Albert MA, et al. 2019 ACC/AHA Guideline on the Primary Prevention of Cardiovascular Disease: a report of the American College of Cardiology/American Heart Association Task Force on Clinical Practice Guidelines. Circulation 2019;140:e596-646.
38. Meschia JF, Bushnell C, Boden-Albala B, et al.; American Heart Association Stroke Council; Council on Cardiovascular and Stroke Nursing; Council on Clinical Cardiology; Council on Functional Genomics and Translational Biology; Council on Hypertension. Guidelines for the primary prevention of stroke: a statement for healthcare professionals from the American Heart Association/ American Stroke Association. Stroke 2014;45:3754-832.

39. Bibbins-Domingo K; U.S. Preventive Services Task Force. Aspirin use for the primary prevention of cardiovascular disease and colorectal cancer: U.S. Preventive Services Task Force recommendation statement. Ann Intern Med 2016;164:836-45.

40. American Diabetes Association. 10. Cardiovascular disease and risk management: Standards of Medical Care in Diabetes - 2019. Diabetes Care 2019;42:S103-23.

41. Vandvik PO, Lincoff AM, Gore JM, et al. Primary and secondary prevention of cardiovascular disease: Antithrombotic Therapy and Prevention of Thrombosis, 9th ed: American College of Chest Physicians Evidence-Based Clinical Practice Guidelines. Chest 2012;141:e637S-68S.
Authors: Theodore Wein MD, M. Patrice Lindsay RN PhD, David G. Gladstone MD PhD, Alexandre Poppe MD CM, Alan Bell MD, Leanne K. Casaubon MD MSc, Norine Foley MSc, Shelagh B. Coutts MD MBChB, Jafna Cox MD, James Douketis MD, Thalia Field MD MHSc, Laura Gioia MD MSc, Jeffrey Habert MD, Eddy Lang MD MDCM, Shamir R. Mehta MD MSc, Christine Papoushek PharmD, William Semchuk PharmD MSc, Mikul Sharma MD MSc, Jacob A. Udell MD MPH, Stephanie Lawrence BA Dip. J., Anita Mountain MD, Gord Gubitz MD, Dar Dowlatshahi MD PhD, Anne Simard MHSC BJ, Andrea de Jong RN MN, Eric E. Smith MD $\mathrm{MPH}$; for the Heart and Stroke Foundation of Canada in collaboration with the Canadian Stroke Consortium.

Competing interests: Theodore Wein reports receiving grants from Allergan, Boehringer Ingelheim and Bayer, and grants and consulting fees from Servier, Allergan and Ipsen; conducting accredited continuing medical education sessions for Servier; and receiving travel reimbursement from Servier. David Gladstone reports no personal financial relationships with industry in the 36 months prior to publication. He serves as principal investigator of the SCREEN-AF trial (uncompensated; trial funded by the Canadian Stroke Prevention Intervention Network (C-SPIN), which is funded by the Canadian Institutes of Health Research [CIHR]), and as a national co-principal investigator for the Canadian arm of the ARCADIA trial, which is funded by the National Institutes of Health. Dr. Gladstone previously served as an independent medical safety monitor for that trial (uncompensated); principal investigator of a research grant from the CIHR-funded C-SPIN Network for the Ontario Holter/Echo Database; and a local site investigator for NAVIGATE ESUS, and NASPAF-ICH (all site fees paid to institution). Alexandre Poppe is site principal investigator and site co-investigator for NoNo and Bayer and has received a grant from Canadian Stroke Trials for Optimized Results. Alan Bell reports receving personal fees from AstraZeneca Novartis, Pfizer, Servier and Bayer, outside the submitted work. He is the vice-president of Thrombosis Canada (unpaid position), serves on the board of directors of Hypertension Canada (unpaid position) and was an author of the Antiplatelet Guideline of the Canadian Cardiovascular Society. Leanne K Casaubon reports receiving personal fees from Medtronic and Bayer and is site principal investigator for a clinical trial related to NA1 by NoNo Inc. (no personal financial compensation). James Douketis reports receiving personal fees from Leo Pharma, Janssen, Pfizer, Bristol-Myers Squibb, Sanofi, Servier Canada and Portola, which are deposited in hospital-based (St. Joseph's Healthcare Hamilton) and university-based (McMaster University) research accounts or charitable foundations. Dr. Douketis also reports receiving personal fees as an employee of The Merck Manual and UpToDate. Thalia Field reports receiving grants and personal fees from Bayer Canada, and personal fees from Pfizer-BMS and Servier, outside the submitted work. Jeffrey Habert reports receiving personal fees from Pfizer, Amgen, BMS, Bayer, Boehringer Ingelheim, Eli-Lilly, Purdue, Allergan, AstraZeneca, Lundbeck, Novo-Nordisk, Servier, Janssen, Roche, HLS,
Otsuka (speaker, advisory board or consulting), and from Alliance, MDBriefcase, Bausch, Liv, MedPlan, Brandaide, Academy, Bridge, Seacourses, Meducom, the International Centre for Professional Development in Health and Medicine, CPD Network, Antibody, CHRC, STA Healthcare Communications, CTC, Canadian Collaborative Research Network, Four Health Comm (scientific committee, consulting), outside the submitted work. Shamir Mehta reports receiving grants and personal fees from AstraZeneca, grants from Boston Scientific, and personal fees from Bayer. William Semchuk reports receiving personal fees from Bayer, Pfizer, Servier, BMS, Sanofi, and AstraZeneca, outside the submitted work. Mikul Sharma reports receiving grants and honoraria from Bayer, grants from Boehringer Ingelheim and Bristol-Myers Squibb, and consulting fees from Portola and Daiichi Sankyo. Jacob Udell reports receiving grants and personal fees from AstraZeneca, Boehringer Ingelheim, Janssen and Sanofi. Eric E Smith has received personal fees from Portola Pharmaceuticals and Biogen. Dar Dowlatshahi has received a grant from the Heart and Stroke Foundation of Canada and honoraria from Bayer, BMS and Apopharma, outside the submitted work. Gord Gubitz is a member of advisory boards for Bayer, Boehringer Ingelheim and Pfizer. No other competing interests were declared.

This article has been peer reviewed.

Affiliations: Department of Neurology and Neurosurgery (Wein), McGill University, Montréal, Que.; the Heart and Stroke Foundation of Canada (Lindsay, Lawrence, Simard, de Jong); Division of Neurology (Gladstone, Casaubon), Department of Medicine, University of Toronto; Division of Neurology (Gladstone), Department of Medicine, Regional Stroke Centre; Hurvitz Brain Sciences Program (Gladstone), Sunnybrook Health Sciences Centre; Sunnybrook Research Institute (Gladstone); Toronto, Ont.; Centre hospitalier de l'Université de Montréal (CHUM) (Poppe, Gioia), Hôpital Notre-Dame, Montréal, Que.; Department of Family Medicine (Bell, Habert), University of Toronto; Toronto Western Hospital Stroke Program (Casaubon), University Health Network, Toronto, Ont.; workHORSE Consulting Ltd. (Foley), London, Ont.; Department of Clinical Neurosciences (Coutts, Smith), Cumming School of Medicine, University of Calgary, Calgary, Alta.; Faculty of Medicine (Cardiology) (Cox), Dalhousie University, Halifax, NS; Department of Medicine (Douketis), McMaster University, Hamilton, Ont.; Division of Neurology (Field), Department of Medicine, University of British Columbia; Vancouver, BC; Department of Emergency Medicine (Lang), Cumming School of Medicine, University of Calgary, Calgary, Alta.; Division of Cardiology (Mehta), Department of Medicine, McMaster University, Hamilton, Ont.; Department of Family and Community Medicine (Papoushek), Leslie Dan Faculty of Pharmacy, University of Toronto, Toronto, Ont.; College of Pharmacy (Semchuk), University of Saskatchewan, Saskatoon, Sask.; Division of Neurology (Sharma), Department of Medicine, McMaster University, Hamilton, 
Ont.; Cardiovascular Division (Udell), Department of Medicine Women's College Hospital; Peter Munk Cardiac Centre (Udell), Toronto General Hospital, University of Toronto, Toronto, Ont.; Divisions Physical Medicine and Rehabilitation) (Mountain) and Neurology (Gubitz), Department of Medicine, Dalhousie University; Division of Neurology (Dowlatshahi), Faculty of Medicine, University of Ottawa, Ottawa, Ont.

Contributors: Theodore Wein is chair of the Acetylsalicylic Acid (ASA) for Primary Prevention of Vascular Events expert writing group and lead author, contributing to all aspects of the conception and design of the work; the acquisition, analysis and interpretation of the data; and the drafting of the recommendations and this manuscript. M. Patrice Lindsay is corresponding author, senior editor of the Canadian Stroke Best Practice Recommendations guidelines and this manuscript, and was involved in all aspects of scientific literature review, writing group deliberations, the external review process and manuscript preparation, and was a writer of supplementary documentation. Eric Smith is senior author of this manuscript and co-chair of the Canadian Stroke Best Practice Advisory Committee, contributing to all aspects of the conception and design of the work; the acquisition, analysis and interpretation of the data; and the drafting of the recommendations and this manuscript. Norine Foley conducted the evidence searches and created the evidence tables for the writing group, as well as contributed to all aspects of the drafting of this manuscript. David Gladstone, Alexandre Poppe, Alan Bell, Leanne Casaubon, Shelagh Coutts, Jafna Cox, James Douketis, Thalia Field, Laura Gioia, Jeffrey Habert, Eddy Lang, Shamir Mehta, Christine Papoushek, William Semchuk, Mikul Sharma, Jacob Udell, Andrea de Jong and Anne Simard actively participated in the expert writing group involved in analyzing the evidence, reviewing drafts and developing the final set of recommendations. Anita Mountain, Gord Gubitz and Dariush Dowlatshahi are senior members of the Canadian Stroke Best Practice Advisory Committee and provided inputs throughout development of these recommendations and reviewed draft documents for approval. Stephanie Lawrence contributed to the drafting of this manuscript and related communications and knowledge translation materials. All of the authors gave final approval of the version to be published and agreed to be accountable for all aspects of the work.

Funding: The development of the Canadian Stroke Best Practice Recommendations is funded in its entirety by the Heart and Stroke Foundation of Canada. No funds for the development of these guidelines are received from commercial interests, including pharmaceutical and medical device companies. Members of the recommendation writing groups and external reviewers are volunteers and do not receive any remuneration for participation in guideline development, updates and reviews.
Endorsement: These guidelines are endorsed by the Canadian Stroke Consortium, Canadian Cardiovascular Society, Thrombosis Canada, Canadian Society of Hospital Pharmacists, the Canadian Pharmacists Association and the Nurse Practitioners' Association of Ontario.

Acknowledgements: The Heart and Stroke Foundation of Canada gratefully acknowledges the ASA for Primary Prevention of Vascular Events writing group leaders and members, all of whom have volunteered their time and expertise to the update of these recommendations. The foundation is especially grateful to the members of the Community Consultation and Review Panel who reviewed all sections of this module and shared their personal experiences and insights on what did or would have made their journey optimal. The members included Cheryl Beattie, Jennifer Bogart, Dan Dobbin, Glen Hilton, Judy Hilton, Allan Morrison and Anjie Valgardson. Members of the Canadian Stroke Consortium, Canadian Cardiovascular Society, Thrombosis Canada and the Canadian Society of Hospital Pharmacists were involved in the development of these recommendations. The foundation thanks the Canadian Pharmacists Association for its review of the draft guidelines. These recommendations underwent external review by Lana Castellucci, Robert Cote, Kim Connelly, John Eikelboom, Michael E. Farkouh, Karen Harkness, Robert Hegele, Andrew Krahn, Gabriela Lewin, Louise McCullough, Kara Nerenberg, Wieslaw Oczkowski, Stephen Phillips, Heather Purvis, Elissa Weinberg and Heather Williams. The foundation also thanks the Canadian Stroke Best Practices and Quality Advisory Committee members, including Eric Smith, Anita Mountain, Leanne K. Casaubon, Gord Gubitz, Dar Dowlatshahi, Dylan Blacquiere, Thalia Field, Louise Clément, Farrell Leibovitch, Christine Papoushek, Jeffrey Habert, Barbara Campbell, Joyce Fung, Michael Hill, Tim Hillier, Eddy Lang, Pascale Lavoie, Beth Linkewich, Colleen O'Connell, Melanie Penn, Jai Shankar, Debbie Timpson, Theodore Wein and Katie White, for their internal review and guidance throughout this process. The foundation acknowledges and thanks Norine Foley and the evidence analysis team at workHORSE; Colleen Norris for her contributions on the considerations regarding sex and gender in the available evidence; Laurie Charest of the Heart and Stroke Foundation of Canada for her coordination of the Canadian Stroke Best Practice Recommendations teams and processes; and the foundation internal teams who contributed to the development of these recommendations and publication: Communications, Creative Services, Translation, Promote Recovery, Health Policy and Digital Solutions.

Correspondence to: M. Patrice Lindsay, patrice.lindsay@heartandstroke.ca 